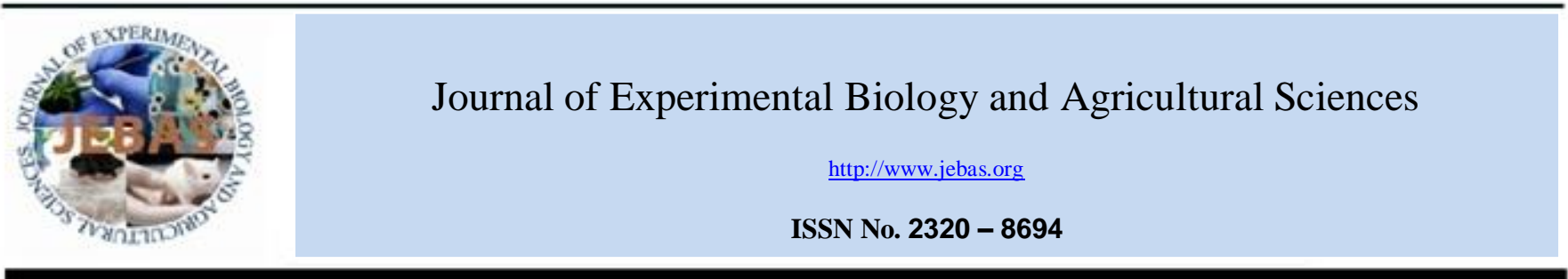

\title{
IDENTIFICATION OF WIDELY ADAPTABLE DOLICHOS BEAN (Lablab purpureus (L.) SWEET VAR. LIGNOSUS) RECOMBINANT INBRED LINES (RILS)
}

\section{Pranesh, Ramesh S*, Anilkumar C}

Department of Genetics and Plant Breeding College of Agriculture, University of Agricultural Sciences, GKVK, Bengaluru, India

Received - September 22, 2018; Revision - October 29, 2018; Accepted - November 25, 2018

Available Online - December 15, 2018

DOI: http://dx.doi.org/10.18006/2018.6(6).912.918

KEYWORDS
Adaptability
GGE biplot
Genotype $\times$ Location
interaction
RILs
AMMI

\begin{abstract}
Crop cultivar performance varies with the production environments represented by temporal (years) and/or spatial (location) variation i.e., genotype $\times$ environment interaction (GEI). GEI is a norm rather than exception for most quantitative traits in crops including dolichos bean, one of the most important legume crops in India. Eight promising recombinant inbred lines (RILs) along with two released varieties were evaluated for fresh pods plant ${ }^{-1}$ and fresh pod yield plant ${ }^{-1}$ at four locations representing eastern and southern dry zones of Karnataka, India to detect and characterize RIL $\times$ location interaction and to identify those with specific and/or wide adaptation. AMMI model and GGE-biplot were used for graphical (visual) assessment of patterns of adaptability of RILs. AMMI II model was adequate to explain the interaction of RILs with locations. The genotypes, RIL 43 and RIL 80 are the best ones at Bengaluru and Hassan, respectively and RIL 52 was the best performer at Chintamani, RIL 77 was the best performer at Mandya for both the traits. The RIL 1, RIL 80 and RIL 111 were widely adapted across all the four locations although they were not significantly better than the released varieties. These RILs could be preferentially used to develop pure-line varieties with broad adaptation.
\end{abstract}

* Corresponding author

E-mail: ramesh_uasb@rediffmail.com (Pranesh Ramesh S)

Peer review under responsibility of Journal of Experimental Biology and Agricultural Sciences.

Production and Hosting by Horizon Publisher India [HPI] (http://www.horizonpublisherindia.in/).

All rights reserved.
All the article published by Journal of Experimental Biology and Agricultural Sciences is licensed under a Creative Commons Attribution-NonCommercial 4.0 International License Based on a work at www.jebas.org.

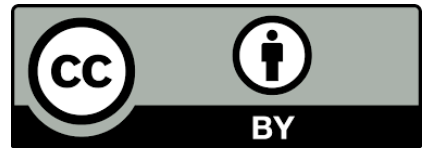




\section{Introduction}

Dolichos bean var. lignosus is one of the important food grain legumes southern districts of Karnataka in India (Ramesh \& Byregowda, 2016). It is predominantly grown as a rainfed crop for fresh beans for use as a vegetable. Fresh dolichos beans are one of the most important sources of protein to a large number people, especially those who depend on vegetarian diets. Fresh pods are harvestable economic products in dolichos bean. Limited area planted to this crop and efforts towards its genetic improvement (Ramesh \& Byregowda, 2016) truly qualities its tag as an underutilized crop. Sustainable production of dolichos bean requires (among others) the use of cultivars with higher yield coupled with wide adaptation and high stability. However crops' (including dolichos bean) cultivars' performance varies with the production environments represented by temporal (years) and/or spatial (location) variation; the phenomenon is widely referred as genotype $\times$ environment interaction (GEI) (Lin \& Binns, 1988; Crossa et al., 1990). GEI is a norm rather than exception for most quantitative traits in crops (Bernardo, 2010) including dolichos bean.

The cultivars that maintain consistent performance across temporal and spatial environments is widely referred to as stable and widely adaptable, respectively (Lin \& Binns, 1988). The objectives of the present study are to (1) characterize GEI pattern s of selected dolichos bean recombinant inbred lines (RILs) and (2) identify RILs with wide/specific adaptation using Additive Main and Multiplicative Interaction (AMMI) model (Gouch \& Zobel, 1988) and genotype + GEI (GGE) biplot (Yan et al., 2000).

\section{Material and methods}

\subsection{Experimental material}

Eight best performing selected RILs which are derived from HA 10-8 $\times$ RIL 3-180 and two released varieties (HA 3 and HA 4) constituted material for the study. While HA 10-8 is an advanced breeding line derived from HA $4 \times$ GLI 151, RIL 3-180 is derived from HA $4 \times$ CPI 31113. All the selected RILs and the released varieties are photoperiod insensitive to flowering time with determinate growth habit.

\subsection{Methods}

The seeds of eight RILs and two released varieties were evaluated in the experimental plots of Colleges of Agriculture located at Bengaluru, Chintamani, Mandya and Hassan in randomized complete block design with two replications. Each entry consisted of 12 plants per replication. Five plants were randomly chosen from each replication and data on fresh pods plant ${ }^{-1}$ and fresh pod yield plant ${ }^{-1}$ were recorded based on the descriptors (Byregowda et al., 2015).

\subsection{Statistical analysis}

The means of genotypes were subjected to analysis of variance (ANOVA) following AMMI II model (Gouch \& Zobel, 1988) to detect and characterize the patterns of GLI. All the analyses were implemented using Genstat software version 12. The observed performances of each RIL and checks at each location were compared with those estimated based on AMMI II model ignoring noise/residual $\left(\mathrm{E}_{\mathrm{ij}}\right)$ to examine the adequacy of model. The performance of $i^{\text {th }}$ genotype in $j^{\text {th }}$ environment $\left(\widehat{P}_{\mathrm{ij}}\right.$ ) based on AMMI II model was estimated as

$$
\widehat{P}_{i j}=\mu+g_{i}+e_{i}+\sum_{n=1}^{N}\left(I P C A_{n}^{g e n_{i}}\right)\left(I P C A_{n}^{e n v_{j}}\right)
$$

Where, $\mu, \mathrm{g}_{\mathrm{i}}, \mathrm{e}_{\mathrm{j}}$ take the same meaning as explained in the model, $I P C A_{n}^{g e n_{i}}$ and IPCA $A_{n}^{e n v_{j}}$ are interaction PCA of $\mathrm{i}^{\text {th }}$ genotype and $\mathrm{j}^{\text {th }}$ environment, respectively.

Patterns of GLI were interpreted based on Genotype + GLI (GGL) biplot. GGE biplot is an effective tool for (1) evaluation of test environments, (2) evaluation of test genotypes and (3) identification of genotypes with specific/wide adaptation (Yan et al., 2000; Yan, 2001).

\section{Results and Discussion}

\subsection{Ammi Anova}

The per cent variance attributable to GLI towards total variability of the genotypes was higher than that attributable to main effects of genotypes and locations for fresh pods per plant ${ }^{-1}$ and fresh pod yield plant ${ }^{-1}$ (Table 1). Most variation attributable to GLI was captured by the two IPCs indicating the adequacy of AMMI II model for both the traits. Vaijayanthi et al. (2016) and Vaijayanthi et al. (2017) also reported that first two IPCs captured most of variation attributable to germplasm accessions $\times$ location interaction in dolichos bean. One of the objectives of AMMI analysis is to obtain an improved estimate of performance of a genotype in a particular environment. The rationale behind AMMI approach is that observed performance of a genotype in a particular environment is not the best estimate of the true performance of the genotype in that environment. This rationale is based on dissection of $(\mathrm{GLI})_{\mathrm{ij}}$ into two components. The first component is due to repeatable patterns of $(\mathrm{GLI})_{\mathrm{ij}}$ captured by first few IPCs. The second component which is called 'noise' is due to non-repeatable $(\mathrm{GLI})_{\mathrm{ij}}$ not captured by IPCs. An improved estimates of the performance of genotypes at each test locations 
Table 1 AMMI ANOVA of dolichos bean recombinant inbred lines (RILs) derived from HA 10-8 × RIL 3-180 for fresh pods and fresh pod yield plant ${ }^{-1}$

\begin{tabular}{|c|c|c|c|c|c|c|c|c|c|}
\hline \multirow[b]{2}{*}{ Source } & \multirow{2}{*}{$\begin{array}{l}\text { Degrees } \\
\text { of } \\
\text { freedom }\end{array}$} & \multicolumn{4}{|c|}{ Fresh pods plant ${ }^{-1}$} & \multicolumn{4}{|c|}{ Fresh pod yield plant $^{-1}$} \\
\hline & & $\begin{array}{l}\text { Mean } \\
\text { sum of } \\
\text { squares }\end{array}$ & $\begin{array}{c}\text { 'F' } \\
\text { Statistic }\end{array}$ & $\mathrm{P} \geq \mathrm{F}$ & $\begin{array}{c}\% \\
\text { variation }\end{array}$ & $\begin{array}{l}\text { Mean } \\
\text { sum of } \\
\text { squares }\end{array}$ & $\begin{array}{c}\text { 'F' } \\
\text { Statistic }\end{array}$ & $\mathrm{P} \geq \mathrm{F}$ & $\begin{array}{c}\% \\
\text { variation }\end{array}$ \\
\hline $\begin{array}{c}\text { Genotypes } \\
\text { (8 RILs }+2 \text { released } \\
\text { varieties) }\end{array}$ & 09 & 14.62 & 01.71 & 00.12 & 04.95 & 176.30 & 03.76 & $2 \times 10^{-3}$ & 04.28 \\
\hline Locations & 03 & 219.54 & 34.83 & $1 \times 10^{-3}$ & 24.79 & 3610.80 & 51.22 & $1 \times 10^{-3}$ & 29.21 \\
\hline $\begin{array}{c}\text { Genotypes } \times \\
\text { Location interaction }\end{array}$ & 27 & 56.80 & 06.65 & $1 \times 10^{-4}$ & 57.74 & 840.40 & 17.94 & $1 \times 10^{-3}$ & 61.20 \\
\hline IPCA 1 & 11 & 94.51 & 11.07 & $1 \times 10^{-3}$ & 67.79 & 1454.5 & 31.05 & $1 \times 10^{-3}$ & 70.51 \\
\hline IPCA 2 & 09 & 46.67 & 05.47 & $1 \times 10^{-4}$ & 27.39 & 612.4 & 13.07 & $1 \times 10^{-3}$ & 24.28 \\
\hline Residual & 07 & 10.55 & 01.24 & 00.31 & & 168.6 & 03.60 & $4 \times 10^{-3}$ & \\
\hline Error & 36 & 08.54 & & & & 46.8 & & & \\
\hline
\end{tabular}
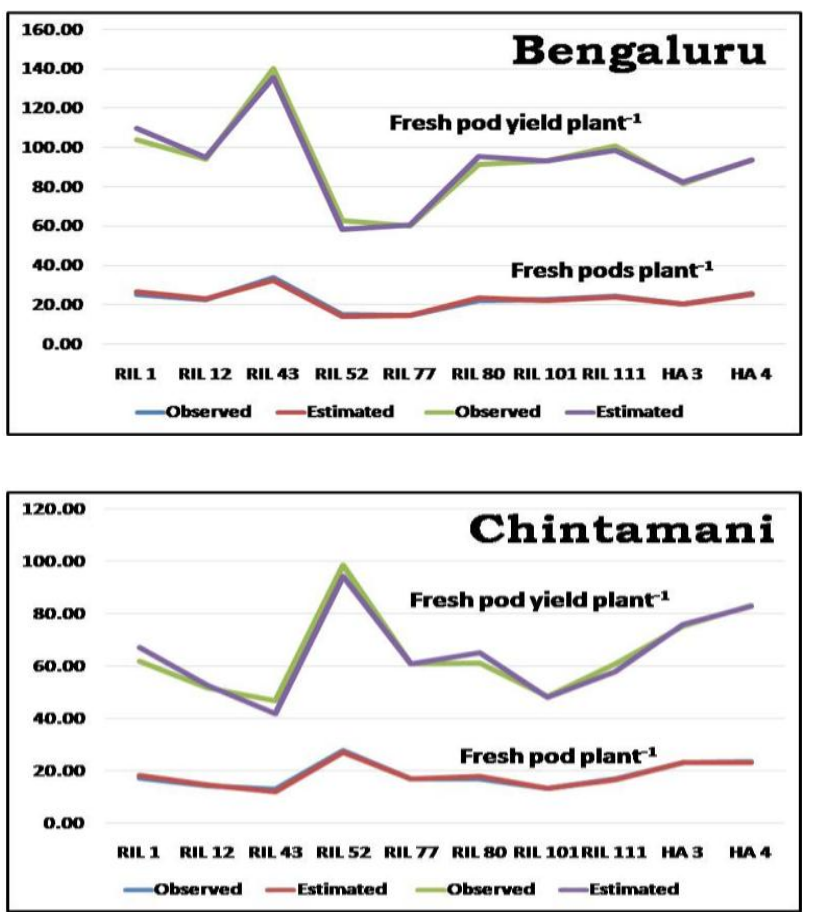
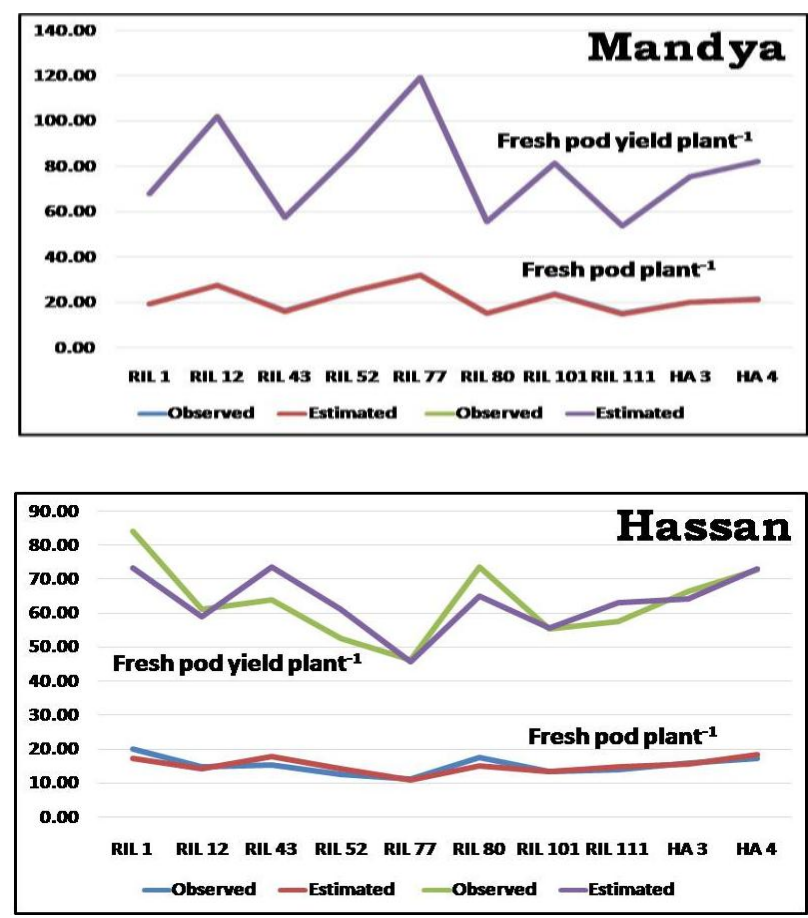

Figure 1 Graphs depicting observed and AMMI II model-based estimates of fresh pods and fresh pod yield plant ${ }^{-1}$ of RILs and released varieties in dolichos bean.

can therefore be obtained by retaining only the component due to repeatable $(\mathrm{GLI})_{\mathrm{ij}}$ (Bernardo, 2010). A good correspondence between observed performances of RILs and checks with those estimated (Figure 1) not only confirmed the adequacy, but also predictability of AMMI II model. Sneller \& Dombek, (1995) could successfully predict performance of soybean genotypes in a given location based on the AMMI II model. A very high variation attributable to GLI and the adequacy of AMMI II model justifies the analysis of adaptability patterns of RILs and the checks and interpretations thereof.

3.2 GGL bi-plot-based patterns of interaction of genotypes with locations

The difference in genotypes adaptability to locations can be qualitatively assessed using the GGE-biplot (Yan et al., 2000) 


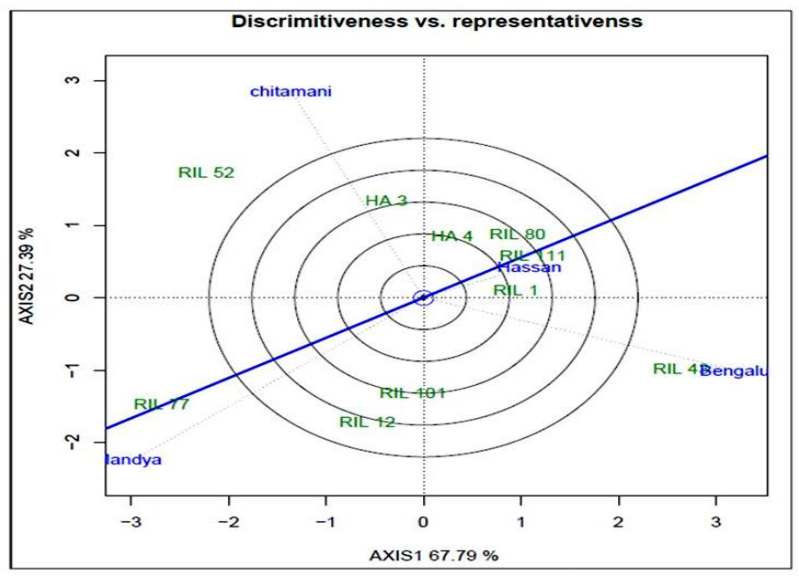

Figure 2 Discriminative vs. representativeness view of GGL bi-plot for fresh pods plant ${ }^{-1}$.

graphical representation that scatters the genotypes according to their IPC scores (Vita et al., 2010). GGE-biplot, hereafter referred to as GGL is a multivariate analytical tool that graphically displays interaction between each genotype and each location in a two-dimensional biplot. It allows visualization of the interrelationship among locations, and the inter-relationship between genotypes and locations using (1) discriminative and representative view of GGL-biplot, (2) average environment coordination (AEC) view of GGL-biplot for identification of genotypes relative to ideal genotypes, (3) AEC view of GGLbiplot for determining mean performance of the genotypes $v s$. their adaptability patterns and (4) polygon view of GGL-biplot for determining 'which-won-where' patterns of genotypes. Based on the aforesaid GGL-biplot views, discriminativeness and representativeness of test locations, identification of genotypes relative to ideal genotypes, determination of mean performance of the test genotypes relative to their adaptability patterns and genotypes that are specifically adapted to each location and those that are adapted across all the locations are discussed in the following sections.

\subsection{Discriminativeness and representativeness view of GGL bi-plot}

Assessment of discriminating and representativeness of test locations is based on the length of environment (here after referred to as location) vectors, and the angle between the test location vectors and AEC in the GGL bi-plot. The lines that connect the test location points to the origin of GGL bi-plot is referred to as location vectors. A single-arrowed line (ray) passing through the origin of the bi-plot is referred as AEC. The average environment is represented by the small circle at the end of the arrow (Yan \& Tinker, 2006). Shorter and longer locations vectors

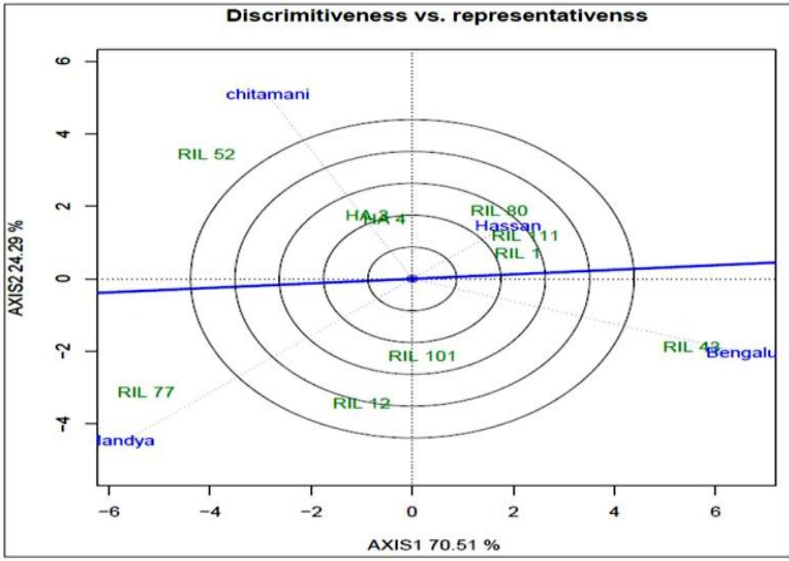

Figure 3 Discriminative vs. representativeness view of GGL bi-plot for fresh pod yield plant ${ }^{-1}$.

indicate lower and higher discriminating ability of the locations, respectively. Location vectors with smaller and larger angles with AEC suggest most and least representativeness of test locations, respectively. Similarly, acute and obtuse angles between the vectors of test locations indicate similarity and dissimilarity/no relationship between the test locations, respectively. In the present study, Mandya was both representative and most discriminative location for both fresh pods plant ${ }^{-1}$ and fresh pod yield plant ${ }^{-1}$ (Figures $2 \& 3$ ). On the contrary, Hassan is the most representative but least discriminative location for both traits while Chintamani was least representative and average discriminative, Bengaluru was average representative and average discriminative for both the traits. These results warrant twopronged approach of breeding dolichos bean to maximize productivity. Hassan could be avoided as a testing location as it cannot discriminate the genotypes. However, varieties can be bred for broad adaptation to three locations (barring Chintamani). Such strategies of breeding for wide adaptation saves substantial the land, human and financial resources while enabling rapid genetic gain per unit time. However, separate breeding programme is warranted for maximizing dolichos bean productivity at Chintamani as it is least representative of the target environment used for testing the genotypes.

\subsection{Genotypes relative to ideal genotype (s)}

An ideal genotype should have both high mean performance and wide adaptation. An ideal genotype (center of concentric circles) is the point on AEC (wide adaptation) in the GGL bi-plot in the positive direction and has a vector length equal to the longest vector of the genotypes on the positive side of AEC. Using the ideal genotype as the center, concentric circles are drawn to help visualize the distance between each genotype and ideal genotype. 


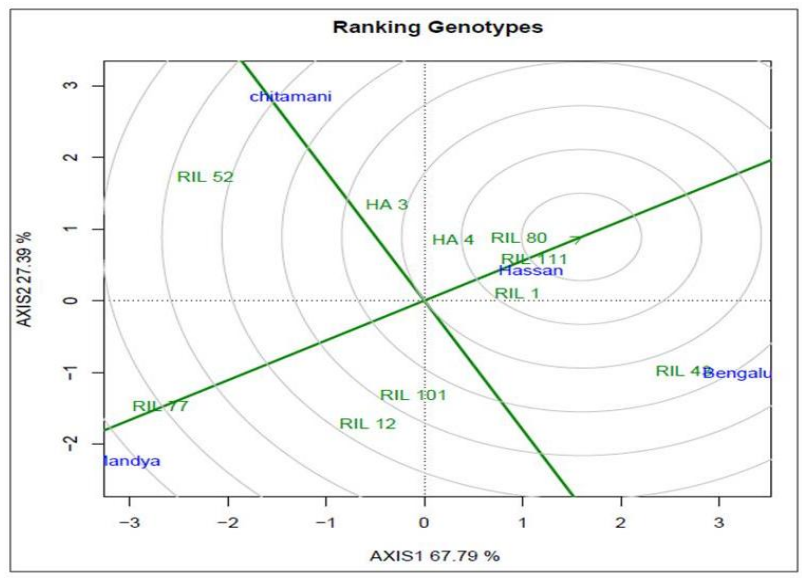

Figure 4 Average environment coordination (AEC) view of GGL bi-plot based on genotype-focused scaling for comparison of genotypes with the ideal genotype for fresh pods plant ${ }^{-1}$.

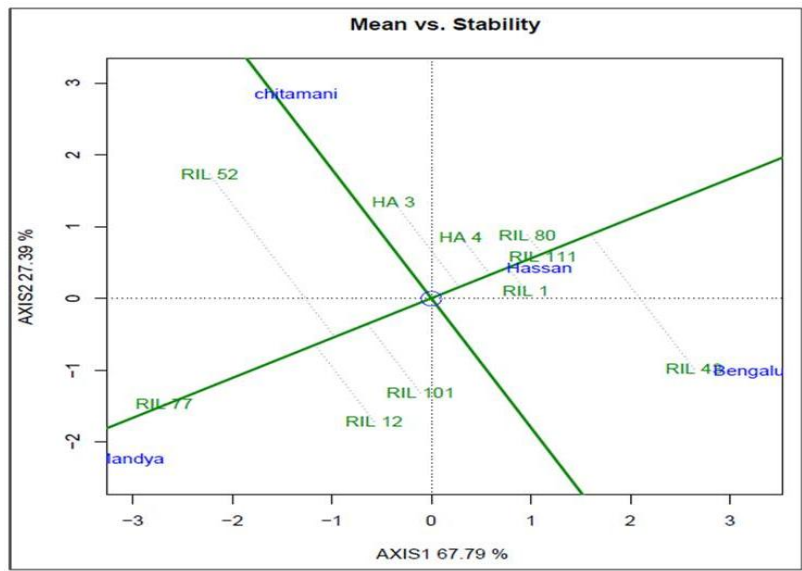

Figure 6 Average environment coordination (AEC) view of GGL bi-plot based on environment-focused scaling for the mean performance $v s$. adaptability for fresh pods plant ${ }^{-1}$.

The genotypes located closer to the "ideal genotype" are more desirable than others. In the present study, RIL 80 and RIL 111 were found ideal genotypes as they were located within the centre of concentric circles (Figure 4). By virtue of their location little away from the center of concentric circles in GGL bi-plot, RIL 1 and HA 4 were identified as near-ideal genotypes for the fresh pods per plant $^{-1}$ (Figure 4). RIL 43 followed by RIL 1, RIL 80 and RIL 111 were identified as near ideal genotypes for fresh pod yield plant $^{-1}$ (Figure 5). However, these RILs were comparable to released varieties (HA 3 and HA 4) for fresh pods plant $^{-1}$ and fresh pod yield plant ${ }^{-1}$. Hence, these RILs could be used in hybridization programme to develop cultivars with wide adaptation. Vaijayanthi et al. (2016) and Vaijayanthi et al. (2017) also identified and reported genotypes relative to ideal genotypes based on GGL-biplot.

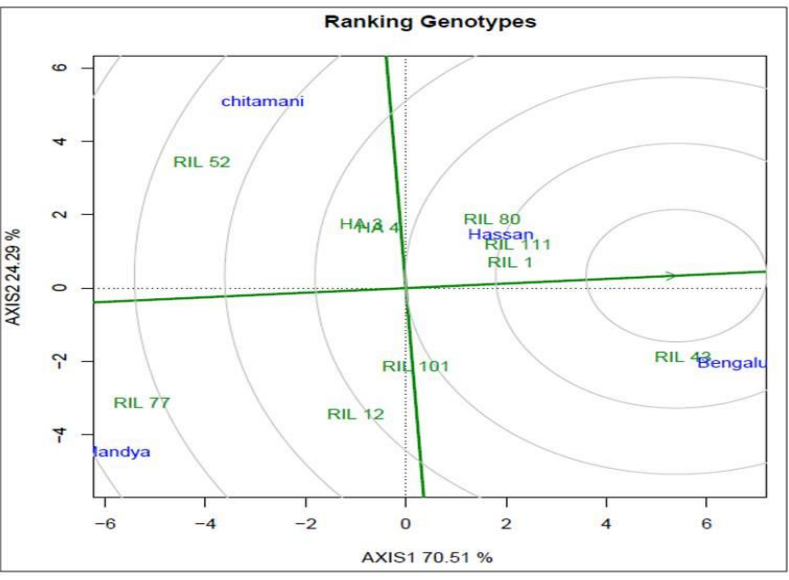

Figure 5 Average environment coordination (AEC) view of GGL bi-plot based on genotype-focused scaling for comparison of genotypes with the ideal genotype for fresh pod yield plant ${ }^{-1}$.

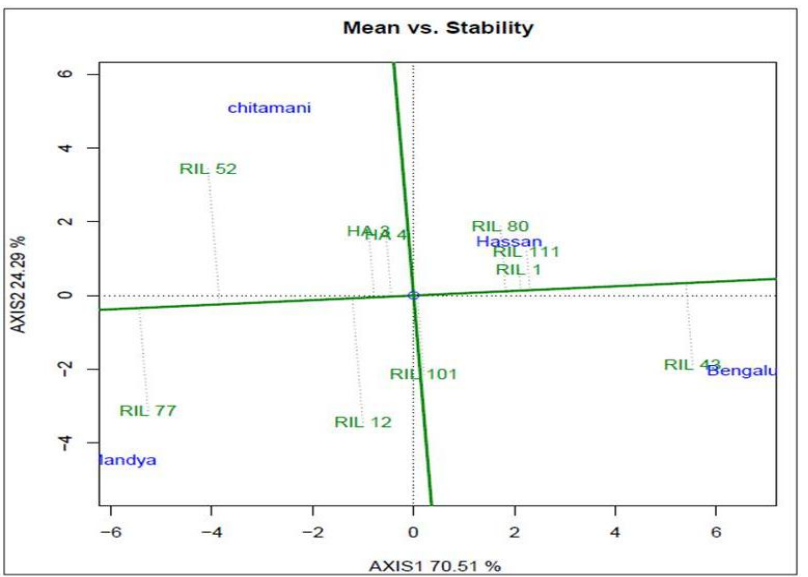

Figure 7 Average environment coordination (AEC) view of GGL bi-plot based on environment-focused scaling for the mean performance $v s$. adaptability for fresh pod yield plant ${ }^{-1}$.

\subsection{Mean performance $v s$. adaptability}

The mean performance and adaptability could be visualized through location of genotypes in relation to AEC view of GGL biplot. The single arrowed AEC points to higher mean performance of the genotypes across locations (Yan, 2001). The genotypes with their points located towards and opposite of AEC arrow are considered to exhibit high and low mean performances, respectively. Further, the relative lengths of projections of the genotypes from AEC are indicative of their relative adaptability. The shorter and longer the absolute projections of genotypes, greater and poorer would be their adaptability, respectively (Yan \& Kang, 2003). In the present study, shorter projections suggested greater and wide adaptability of RIL 1, RIL 80 and RIL 111 followed by HA 4 for fresh pods plant ${ }^{-1}$ (Figure 6) and fresh pod yield plant $^{-1}$ (Figure 7). However, RIL 1, RIL 80 and RIL 111 


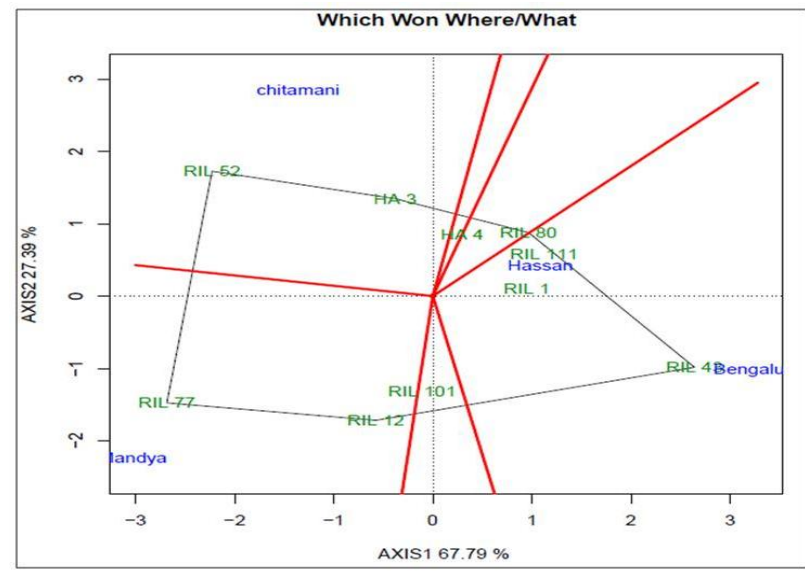

Figure 8 Polygon view of GGL bi-plot based on the symmetrical scaling for 'which won-where' pattern of genotypes and locations for fresh pods plant ${ }^{-1}$.

were comparable to HA 4 for both fresh pods plant $^{-1}$ and fresh pod yield plant $^{-1}$.

\subsection{Which-won-where pattern}

One of the features of GGL bi-plot is its ability to which-wonwhere pattern of a genotype (Yan et al., 2000). This feature is shown by polygon view of the GGL bi-plot. The equality lines divide the bi-plot into sectors. The vertex genotype in each sector is the winning genotype at locations whose markers (point) fall into the respective sector (Yan et al., 2000). Locations within the same sector share the same winning genotype, and locations in different sectors have different winning genotypes, thus polygon view of a GGL bi-plot indicates presence or absence of cross-over GLI (Yan \& Rajcan, 2002). In the present study, the genotypes RIL 43 and RIL 80 are the best ones at Bengaluru and Hassan, respectively (Figures $8 \& 9$ ). RIL 52 was the best performer at Chintamani while RIL 77 was the best performer at Mandya for both the traits. Better performance of different genotypes at different locations clearly suggested the presence of significant cross-over GLI. Vaijayanthi et al. (2016) and Vaijayanthi et al. (2017) have also reported significant cross-over germplasm $\times$ location interaction in dolichos bean. They could identify a few germplasm accessions specifically adapted to locations and few others with high pod yield plant ${ }^{-1}$ and wide adaptation to all the test locations.

Our results suggest broad adaptation of RIL 1, RIL 80 and RIL 111 , although they were not significantly better than the released varieties for fresh pods and fresh pod yield plant ${ }^{-1}$. However, they were comparable to released varieties. These RILs could be preferentially used to develop widely adaptable pure-line varieties significantly better than HA 3 and HA 4 for fresh pods and fresh

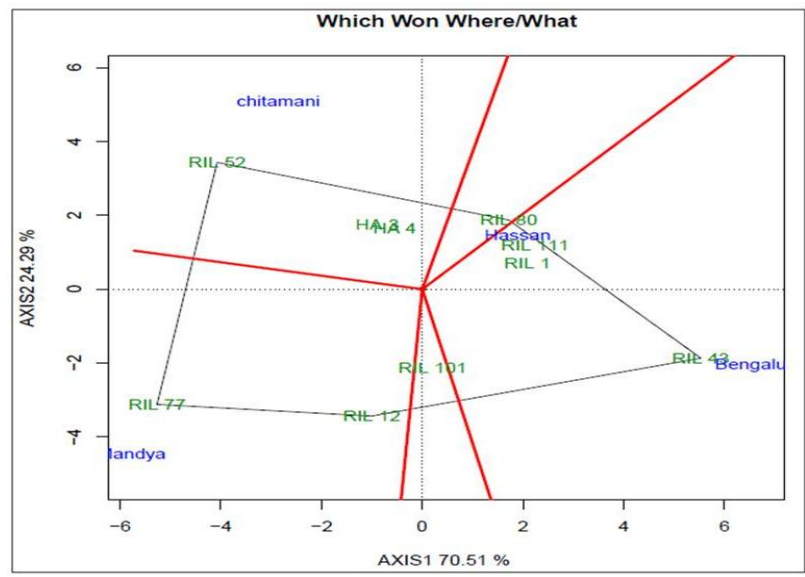

Figure 9 Polygon view of GGL bi-plot based on the symmetrical scaling for 'which won-where' pattern of genotypes and locations for fresh pod yield plant ${ }^{-1}$.

pod yield plant ${ }^{-1}$. Further, Hassan could be avoided as test location in future multi-location trials to identify cultivars with specific/broad adaptation.

\section{Acknowledgement}

The senior author gratefully acknowledges the financial support from University Grants Commission (UGC), New Delhi, India in the form of Rajiv Gandhi National Fellowship (RGNF) for SC candidates [F1-17.1/2015-16/RGNF-2015-17-SC-KAR-24841/(SAIII/Website)] to pursuing $\mathrm{PhD}$ degree in the University of Agricultural Sciences, Bengaluru, India.

\section{Conflict of Interest : Nil}

\section{References}

Bernardo R (2010) Breeding for quantitative traits in plants. Stemma press, Woodbury, Minnesota.

Byregowda M, Girish G, Ramesh S, Mahadevu P, Keerthi CM (2015) Descriptors of dolichos bean (Lablab purpureus L.). Journal of Food Legumes 28: 203-214.

Crossa J, Gauch HG, Zobel RW (1990) Additive main effects and multiplicative interaction analysis of two international maize cultivar trials. Crop Science 30: 493-500.

Gauch HG, Zobel RW (1988) Predictive and postdictive success of statistical analyses of yield trials. Theoretical and Applied Genetics 76: 1-10.

Lin CS, Binns MR (1988) A method for analyzing cultivar $\times$ location $\times$ year experiments: a new stability parameter. Theoretical and Applied Genetics 76: 425-430. 
Ramesh S, Byre Gowda M (2016) Dolichos bean (Labalab purpureus L. Sweet var. Lignosus) genetics and breeding - present status and future prospects. Mysore Journal of Agricultural Sciences 50: 481-500.

Sneller CH, Dombek D (1995) comparing soybean cultivar ranking and selection for yield with AMMI and full data performance estimates. Crop Science 35: 1536-1541.

Vaijayanthi PV, Chandrashekar C, Keerthi CM, Marappa N, Mahadevu P, Chandrakanth (2017) Yield stability analysis of dolichos bean genotypes using AMMI model and GGL biplot. International Journal of Agricultural Science 9: 4800-4805.

Vaijayanthi PV, Ramesh S, Byregowda M, Mohan Rao A, Ramappa HK, Chinnamade Gowda (2016) Identification of selected germplasm accessions for specific/wide adaptation coupled with high pod productivity in dolichos bean (Lablab purpureus L. Sweet). Mysore Journal of Agricultural Sciences 50: 376-380.
Vita PD, Mastrangeola AM, Matteua L, Mazzucotelliba, Yirzi N, Palumboc M, Stortod FR, Cattivelli L (2010) Genetic improvement effects on yield stability in durum wheat genotypes grown in Italy. Field Crops Research 119: 68-77.

Yan W (2001) GGE biplot - A Windows Application for Graphical Analysis of Multi-environment Trial Data and Other Types of Two - Way Data. Agronomy Journal 93: 1111-1118.

Yan W, Hunt LA, Sheng Q, Szlavnics Z (2000) Cultivar evaluation and mega-environment investigation based on the GGE biplot. Crop Science 40: 597-605.

Yan W, Kang MS (2003) GGE Biplot Analysis: A graphical tool for breeders, geneticists, and agronomists. CRC press, USA.

Yan W, Rajcan I (2002) Biplot analysis of test sites and trait relations of soybean in Ontario, Crop Science 42: 11-20.

Yan W, Tinker NA (2006) Biplot analysis of multi-environment trial data: Principles and applications. Canadian Journal of Plant Science 86: 623-645. 